\title{
Consequences of transvaginal follicular puncture on well-being in cows
}

\author{
S. Chastant-Maillard ${ }^{1}$, H. Quinton ${ }^{1}$, J. Lauffenburger ${ }^{1}$, N. Cordonnier-Lefort ${ }^{2}$, \\ C. Richard ${ }^{3}$, J. Marchal ${ }^{3}$, P. Mormede ${ }^{4}$ and J. P. Renard ${ }^{5}$ \\ ${ }^{1}$ Biologie de la Reproduction, UMR INRA/ENVA 1198, Unité Pédagogique de Reproduction and ${ }^{2}$ Unité \\ Pédagogique d'Histologie et d'Anatomie Pathologique, Ecole Nationale Vétérinaire d'Alfort, 7 Avenue du \\ Général De Gaulle, 94704 Maisons-Alfort, France; ${ }^{3}$ Unité Commune d'Expérimentation Animale, \\ Bressonvilliers, Institut National de la Recherche Agronomique, 91630 Leudeville, France; ${ }^{4}$ Laboratoire \\ Neurogénétique et Stress, Institut National de la Santé et de la Recherche Médicale, U471-INRA - \\ Université Victor Segalen, Institut Francois Magendie, 1 Rue Camille Saint Saens, 33077 Bordeaux \\ Cedex, France; and ${ }^{5}$ Biologie du Développement et Biotechnologies, UMR INRA-ENVA 1198, Institut \\ National de la Recherche Agronomique, 78352 Jouy en Josas, France
}

The purpose of this study was to evaluate the impact of repeated follicular puncture used in the ovum pick-up technique on the welfare of cows. The evaluation relies on the physiological measurement of stress, milk production criteria, immune status, and the histological examination of ovaries. Two groups of five Holstein cows were submitted to epidural anaesthesia and genital palpation with insertion of an intravaginal ultrasound probe for transvaginal puncture (the puncture was not performed in the control group). Animals were manipulated twice a week for 8 weeks (16 manipulation sessions). The blood cortisol concentrations increased after each session; however, the concentrations were the same in both the control and the punctured groups. Two adrenocorticotrophic hormone challenge tests, performed before the first session and after the last session, showed an unchanged adrenal sensitivity through repeated puncture sessions. The transvaginal puncture did not affect milk production, or blood and milk somatic cell counts. Ovariectomies were performed on another group of four Holstein cows at various intervals (0 to 30 days) after five similar puncture sessions. Histological examination of the ovaries 4 days after puncture revealed blood-filled follicles and haemorrhagic foci in ovarian stroma, but the examination 30 days after the last puncture session demonstrated very limited, if any, fibrosis. On the basis of the criteria chosen for this study, repeated transvaginal follicular puncture on its own does not impact adversely on the welfare of cows.

\section{Introduction}

Ovum pick-up (OPU), one of the most recently developed biotechnologies for cattle (Pieterse et al., 1988), allows repeated oocyte collection from ovarian follicles in live females. Through the use of this technique, more in-depth studies may be conducted on bovine oocytes than the studies based on oocyte collection at the abattoir. Associated with in vitro fertilization, OPU appears to act as an adequate complement to superovulation and embryo flushing due to a more efficient genetic improvement (Goodhand et al., 1999; Schernthaner et al., 1999) and the need for less hormonal treatment. However, as collected oocytes are used for in vitro production, this procedure requires a specialized

Email: schastant@vet-alfort.fr laboratory and is associated with large offspring syndrome.

As each OPU session necessitates multiple needle punctures of the vagina, the peritoneum and the ovaries, and sessions are typically repeated twice per week for a number of weeks, a significant reticence has developed towards this biotechnology. In fact, only $10-50 \%$ of the European public consider OPU to be acceptable (Den Daas and Callesen, 2000; Van Genderen and De Vriend, 2000). Public concerns likely deal with the artificial manipulation of reproduction as well as the belief that OPU can induce pain or lesions in donor cows. In Denmark, owing to the suspected violation of animal welfare, OPU has been restricted to animal experimentation and is forbidden for use in genetic improvement (Callesen, 1998). As the management of domestic animals raised for commercial purposes becomes a global concern, scientists are asked to 
consider animal welfare. Moreover, scientists must verify the impact of biotechnologies with respect to stress and lesions experienced by animals. However, reliable information on the consequences of new biotechnologies on animal welfare is generally lacking.

During ultrasound-guided oocyte collection, cattle undergo repeated restraint, transrectal palpation, introduction of an intravaginal device, epidural anaesthesia and repeated ovarian punctures. Among these manipulations, transrectal palpation and introduction of an intravaginal device, commonly practised by veterinarians and inseminators, have been shown to induce moderate stress (Alam and Dobson, 1986). Epidural anaesthesia is a less common practice. However, even when repeated (as for OPU performed twice per week), associated lesions seem minor and occur in only a few animals (McEvoy et al., 2001). The most questionable aspect of OPU is the multiple transvaginal and transovarian punctures, which constitute the more invasive and the most specific part of the OPU. Therefore, the aim of this study was to provide a scientific evaluation of the consequences of repeated transvaginal follicular puncture on welfare in cows.

In animals, the perturbation of well-being can be evaluated by the measurement of stress, defined as a disruption of homeostasis or the inability of the animal to cope with its environment (Dobson and Smith, 2000; Tilbrook et al., 2000). Physiologically, stress is evaluated through the neuroendocrine responses it induces, particularly through the activation of the hypothalamo-pituitary-adrenal axis. The stimulation of this axis releases adrenocorticotrophic hormone (ACTH) from the corticotrophs of the anterior pituitary gland. ACTH then acts on the cortex of the adrenal glands to stimulate the synthesis and secretion of glucocorticoids, the most common indicators of stress (Dantzer, 1994; Tilbrook et al., 2000). Blood cortisol concentrations after each manipulation session were closely examined in this study. Moreover, as OPU is usually performed on a repeated basis (twice per week for several weeks), transvaginal puncture could act as a repeated acute stressor. Such a stressor may induce adrenal desensitization, that is, diminution of the hypothalamopituitary-adrenal axis response to ACTH (Ladewig, 1987). In the present study, adrenal sensitivity was tested through two exogenous challenges by ACTH before and after the experimental period, respectively. However, given the complex nature of animal well-being, other criteria were included in the study to conduct a complete evaluation of the consequences of repeated transvaginal puncture on animal well-being: milk production and behaviour of the cows (to evaluate acute stress); milk somatic cell counts and white blood cell counts (to examine the impact of repeated acute stress); and the follow-up of oestrous cycles and histological examination of the ovaries (to evaluate the consequences of punctures on ovaries).

\section{Materials and Methods}

\section{Animals and experimental design}

Ten primiparous, non-pregnant, milking Holstein cows, raised together at the experimental station of Bressonvilliers, were assigned either to the experimental group (transvaginal punctured (TP): five cows) or to the control group (five cows). The cows had never experienced the OPU procedure, and were currently manipulated in chutes. Oestrous cycles were synchronized before the onset of the experimental period by a progestagen implant maintained for 9 days $(3 \mathrm{mg}$ norgestomet, Crestar method ${ }^{\mathrm{TM}}$; Intervet, Angers) with a prostaglandin $\mathrm{F}_{2 \alpha}$ analogue injection 2 days before implant removal (cloprostenol, $500 \mathrm{mg}$ i.m., Estrumate $^{\mathrm{TM}}$; Shering-Plough, Levallois). Punctures started 3 days after the removal of the progestagen.

In the TP group, cows were restrained in a chute, and were administered epidural anaesthesia $(50 \mathrm{mg}$ lidocaïne, Xylovet ${ }^{\mathrm{TM}}$; Ceva, Libourne). OPU (Pieterse et al., 1988) was performed under ultrasonography (Pie Medical 200, VetScan 3, sectorial 7.5 MHz probe; Hospimedi, Pouilly), with a $50 \mathrm{~mm} \mathrm{Hg}$ constant vacuum aspiration through an 18-gauge $\times 1.5(40 \times 1.2 \mathrm{~mm})$ short bevelled needle (Neolus, Terumo, Leuven). As this study was designed to evaluate the specific consequences of repeated transvaginal ovarian punctures, control cows were manipulated in the same manner as TP cows, except that the ovaries were not punctured. Control cows received epidural anaesthesia, a vaginal device the same diameter as the device used in the OPU system, and the ovarian manipulation by transrectal palpation was performed for the same period as for the punctured cows. The only difference between the two groups was the actual puncture of the ovaries. Manipulations were performed twice per week for 8 weeks. These 16 manipulation sessions were designated the 'experimental period'.

Protocol and management of animals was approved by the Committee for Ethics of the National Veterinary School of Alfort.

\section{Blood cortisol measurement}

As Lefcourt et al. (1993) demonstrated circadian and ultradian variations of peripheral cortisol concentrations, all experiments were performed between 08:30 and 12:00 $\mathrm{h}$. One animal from the control group and one from the punctured group were manipulated simultaneously in the same room.

Acute stress was evaluated at the first, fifth, ninth and thirteenth manipulation sessions. Blood collection began immediately after the cow entered the chute and was repeated $0,15,30,60,120$ and 180 min after the end of the manipulation session, which lasted about $15 \mathrm{~min}$. Blood was collected by repeated venepuncture at the caudal vein using sodium heparinate. The blood samples 
were collected by an experienced veterinarian in less than $2 \mathrm{~min}$, to limit any stress caused by the collection procedure (Broom and Johnson, 1993). Samples were placed on ice until they were centrifuged at $3000 \mathrm{~g}$ for 10 min and plasma was then aliquoted and frozen. Cortisol concentrations were measured by an automated ELISA technique (Enzymun-Test cortisol; Roche Diagnostics, Meylan). All samples were analysed in a single batch.

\section{Adrenal sensitivity (repeated acute stress)}

Seven days before the first session and seven days after the last session (the sixteenth session), $1 \mathrm{mg}$ ACTH (Synacthene ${ }^{\text {TM}}$; Ciba-Geigy, Rueil-Malmaison) was injected i.v. into the ten cows. Blood was collected (as described above for acute stress measurement) for the next $310 \mathrm{~min}$ for the measurement of blood cortisol. One blood sample, collected on EDTA immediately before the ACTH injection, was used to conduct a white blood cell count.

\section{Milk production}

Morning and evening milk productions were recorded for each cow during the experimental period with the use of an Agri-Comp 2045 recording system and Agri-Therm software (Bou-Matic Europe, Saint Nom la Breteche). Production after manipulation was measured on the evening after the manipulation session (mean \pm SEM for the five animals in each group). The mean evening production served as the reference and was calculated from the evening milkings for seven days before the manipulation session for the five animals in each group.

\section{Ovarian cyclicity}

At each manipulation session, blood was collected and plasma was separated for progesterone measurement (automated ELISA technique; Enzymun-Test progesterone, Roche) immediately after the entry of the animal into the chute.

\section{Histological examination of ovaries}

Four Holstein cows (unrelated to those observed during the above protocol) were submitted to five OPU sessions, twice per week, using the procedure described above. Ovariectomies were performed at different intervals: immediately after the first of the five OPU sessions, or 4, 11 or 30 days after the last of the five sessions. Three other Holstein cows having undergone 27 sessions (twice per week during 14 weeks) were slaughtered about 8 months after the last puncture session and their ovaries were collected.

The ovaries were fixed in $10 \%$ formaldehyde and embedded in paraffin wax immediately after re-

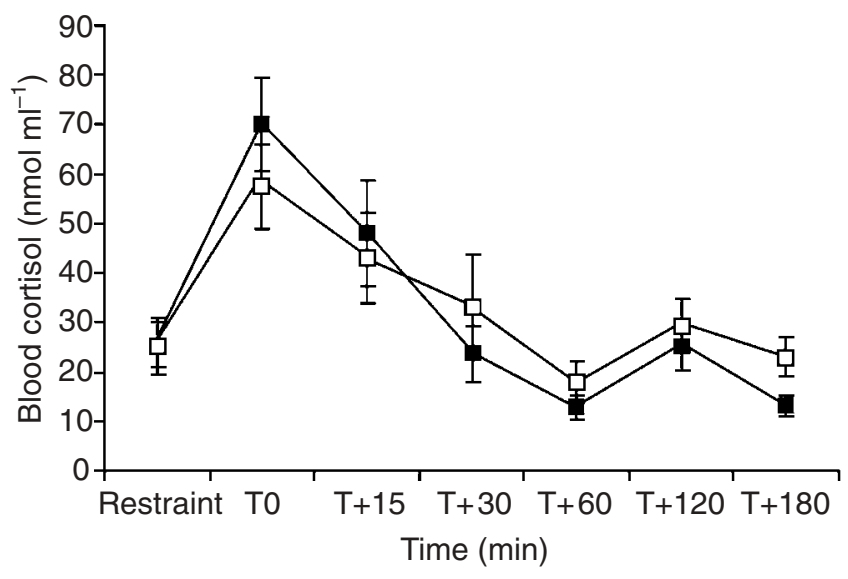

Fig. 1. Blood cortisol concentrations in transvaginal punctured cows (घ) and control cows ( $\square$ ) after the manipulation session. Time is indicated in minutes after the end of the session. Blood cortisol concentrations were measured at the end of the first, fifth, ninth and thirteenth manipulation sessions. Results are the means $( \pm$ SEM) of cortisol values obtained for the five animals in each group in the four chosen sessions. T0: end of the manipulation.

moval. A histological examination was performed after haematoxylin-eosin-safran staining of the slides.

\section{Statistical analysis}

The follow-up of cortisol concentrations was analysed by a repeated measures ANOVA (Crunch Software Co., Oakland, CA). The effects of time, group (TP or control), session number (effect of manipulation repetition) and the interactions between these three factors were tested for measurement of acute stress. The effects of time, group and ACTH test (before the onset or after the end of the experimental period) and their interactions were tested for adrenal sensitivity. Milk production and blood numeration data were analysed by Student's $t$ test (SAS 6.12; SAS Institute, Cary, NY). The level of statistical significance was $P=0.05$.

\section{Results}

\section{Evaluation of acute stress associated with transvaginal puncture}

Plasma cortisol concentrations increased significantly after the manipulation of control and TP cows $(P<$ 0.001). After a peak at the end of the manipulation, cortisol concentrations regularly decreased until $1 \mathrm{~h}$ after the end of manipulation, when they reached basal concentrations (Fig. 1). Even at their peak values, cortisol concentrations did not reach the values induced by ACTH injection (Fig. 2); concentrations remained at least half. There was no significant difference in cortisol concentration between the two groups (no group effect; no interaction between time and group). Moreover, 


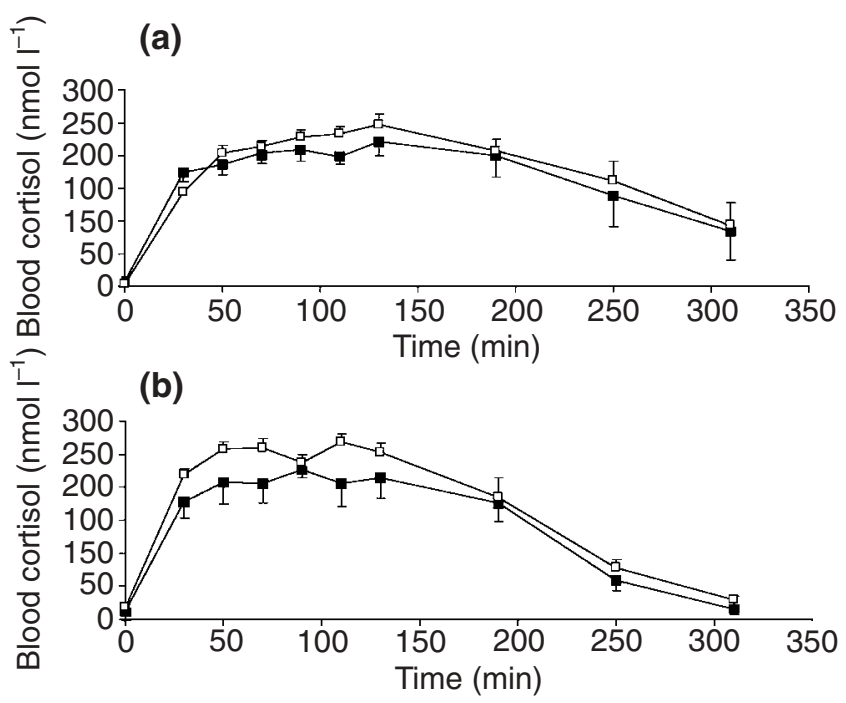

Fig. 2. Adrenal sensitivity of transvaginal punctured cows ( $\mathbf{\square})$ and control cows ( $\square$ ) (a) one week before and (b) one week after the experimental period. Blood cortisol concentrations were measured for $310 \mathrm{~min}$ after the injection of adrenocorticotrophic hormone $(\mathrm{ACTH})$. Results are the mean ( \pm SEM) of values obtained for the five animals in each group. T0: ACTH injection.

cortisol response curves remained identical during the successive manipulation sessions (no interaction between time and session number).

From a behavioural viewpoint, cows undergoing transvaginal puncture did not exhibit any sign of discomfort (some even continued to ruminate during puncture), or any reluctance to enter the place of OPU for the repeated manipulation sessions. The comparison of milk production measured the evening after the manipulation with the mean production calculated from the seven previous evenings (Fig. 3) demonstrated equivalent milk production in both groups before the experiment. A mean decrease of $0.7( \pm 0.4) \mathrm{kg}$ was observed $(6 \%$ of production) in milk production after manipulation $(P<$ $0.01)$, but this decrease was equivalent in the two groups.

\section{Evaluation of repeated acute stress associated with the repetition of transvaginal puncture sessions}

After ACTH injection, blood cortisol concentrations were markedly increased, reaching 200-250 nmol ml $\mathrm{m}^{-1}$ after $1 \mathrm{~h}$ (Fig. 2). Cortisol concentrations remained steady between 1 and $2 \mathrm{~h}$ after stimulation and decreased abruptly at $3 \mathrm{~h}$ and thereafter. The return to baseline occurred after $5 \mathrm{~h}$. No significant difference was observed between the groups before the experimental period (Fig. 2a). The second stimulation test, performed after the end of the experimental period, showed the same general response pattern (Fig. 2b); there was no difference between the two groups. Moreover, adrenal responses

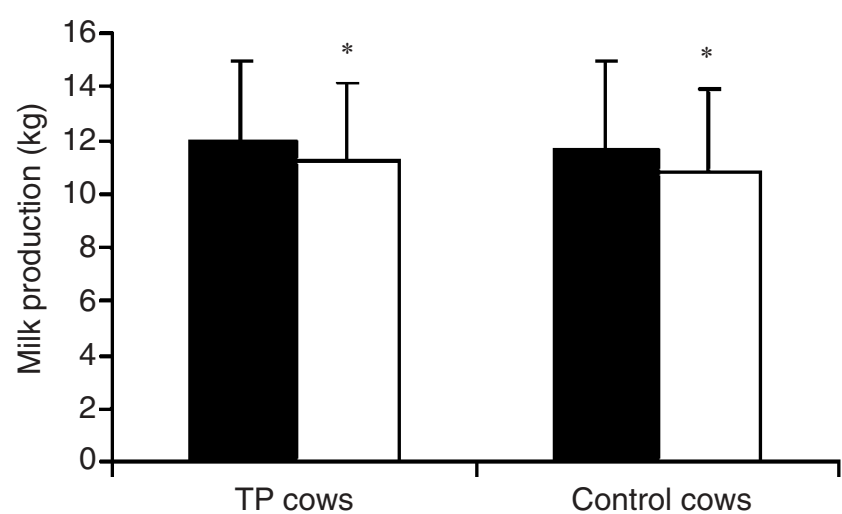

Fig. 3. Influence of transvaginal puncture on milk production in cows. Production was measured the evening after the manipulation session ( $\square$; mean \pm SEM for the five animals in each group). The reference was taken as the mean evening production (ם), calculated as the mean production of the seven evening milkings before the manipulation session. *Significant difference $(P<0.01)$ between mean evening milk production and evening production after manipulation.

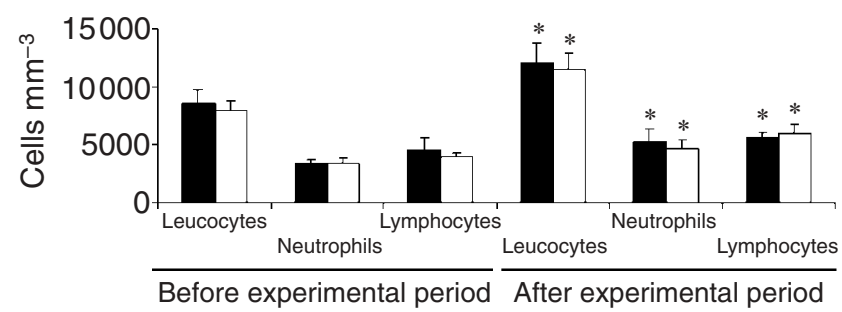

Fig. 4. Influence of transvaginal puncture on white blood cell counts in cows. In both groups (transvaginal puncture (ם) and control $(\square)$ ), the concentrations in leucocytes, neutrophils and lymphocytes were calculated 1 week before the first manipulation session and 1 week after the end of the last manipulation session. * Significant increases in each cell population for both groups during the experimental period $(P<0.05)$. There was no difference between groups before or after the experimental period.

did not differ between the first test (before experimental period) and the second test (performed after 16 sessions; no significant interaction between time and ACTH test number).

The comparison of white blood cell populations and milk somatic cell counts showed that, similar to other criteria, both groups were comparable before the experiment (Figs 4 and 5). Despite a significant increase in white blood cell counts for both groups at the second test (global mean: $8286 \pm 1256$ leucocytes $\mathrm{mm}^{-3}$ at the first numeration versus $11794 \pm 1256$ leucocytes $\mathrm{mm}^{-3}$ at the second; $P<0.01$ ), there was no significant difference between TP and control groups (Fig. 4). In a similar way, the groups showed no difference in milk cell counts before (month 1 ), during (month 2 ) and after (month 3) the experimental period (Fig. 5).

From a clinical viewpoint, during the whole period of the experiment (and even several weeks after), there was 


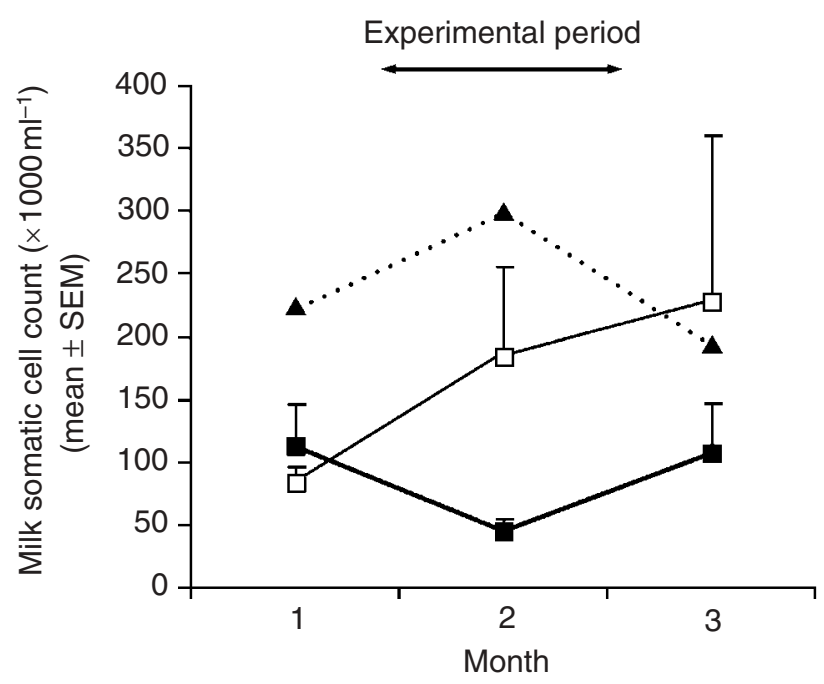

Fig. 5. Milk somatic cell counts during the experimental period in transvaginal punctured cows $(\boldsymbol{\square})$, control cows $(\square)$ and the herd $(\boldsymbol{\Lambda})$. Milk somatic cell counts were recorded for each cow once a month for transvaginal puncture and control groups and for each cow of the whole herd of Bressonvilliers to which the experimental cows belonged. No difference was detected between transvaginal puncture and control groups.

no sign of any mastitis, vaginitis, or abscess at the site of multiple epidural injections.

\section{Consequences on ovarian function}

Ovarian cycles. At the onset of the experimental period on day 3 after implant removal, blood progesterone concentrations were low (Fig. 6). Blood progesterone, a product of the corpus luteum, was present at high concentrations for about 15 days and then decreased and remained at low concentrations after luteolysis during the follicular phase. Ovarian punctures did not seem to impair the development and endocrine activity of the first corpus luteum (Fig. 6; days 3-21). Progesterone concentrations were normal and luteolysis occurred normally. However, whereas control cows exhibited a second increase in blood progesterone concentrations as a consequence of the development of a corpus luteum in the second oestrous cycle (days 21-42), blood progesterone concentrations of TP cows remained low. All five punctured cows came back into oestrous as early as 3-5 days after the end of puncture sessions.

Histological examination of ovaries. Upon performing the ovariectomy, no fibrous adherence or collection of fibrin was observed around the punctured ovaries, regardless of the time that had elapsed since the last puncture session. Haemorrhagic foci were noticed in stroma, together with some blood-filled follicles, among ovaries collected immediately after puncture (Fig. 7a,b).

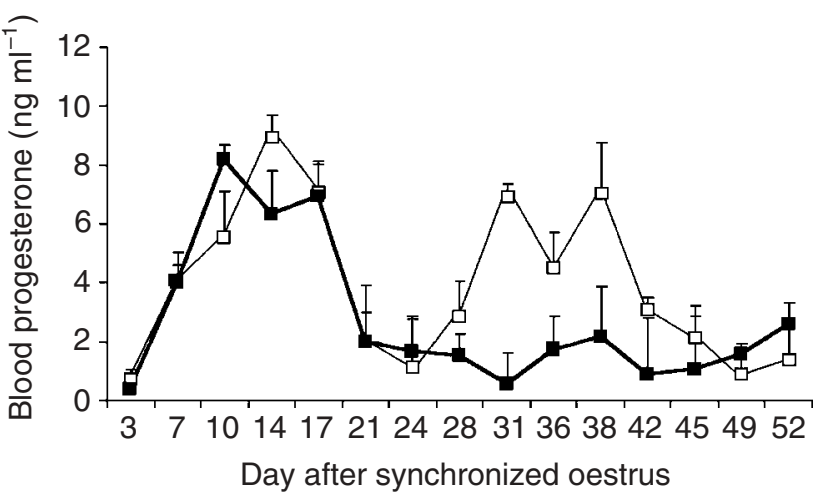

Fig. 6. Plasma progesterone concentrations during the experimental period in transvaginal punctured cows (ם) and control cows ( $\square)$.

An intense vascular congestion was also present. Four days after the last puncture session, haemorrhagic zones were significantly more limited and displayed the onset of connective organization (haemosiderosis, collagen synthesis by young and numerous fibroblasts, numerous neoformed capillaries, afflux of neutrophils; Fig. 7c,d). Eleven days after the last puncture session, some areas of new connective tissue were observed, which were still highly vascularized (Fig. 7e). One month after puncture, foci of fibrosis were of very limited size (Fig. 7f,g).

Among cows submitted to $27 \mathrm{OPU}$ sessions and slaughtered about 8 months after the last puncture session, no abnormal fibrosis was noticed, and the ovaries appeared to be functioning normally, with the presence of follicles at each stage of growth, corpora lutea and albicans.

\section{Discussion}

This study confirms preliminary results (Lauffenburger et al., 1999) by demonstrating that transvaginal puncture does not place more stress on cows undergoing routine procedures for OPU.

A significant activation of the hypothalamo-pituitaryadrenal axis, as reflected by the increased plasma cortisol concentrations, is usually observed during acute stress (Fell et al., 1986; Morisse et al., 1995; Tilbrook et al., 2000), and the intensity of cortisol increase can be used to quantify the intensity of the stress (Chase et al., 1995; Morisse et al., 1995; Fisher et al., 1996). Acute stress was observed in both groups in the present study, but the intensity was low, according to the duration of increased cortisol. This may have been mostly the result of the restraint and isolation experienced in the room in which OPU was carried out, as blood cortisol concentrations were already higher than basal concentrations when measured just after entry into the chute. Even simple veterinary procedures, such as genital palpation, are known to increase adrenocortical activity in cows (Alam and Dobson, 1986). In any case, the intensity of adrenal 

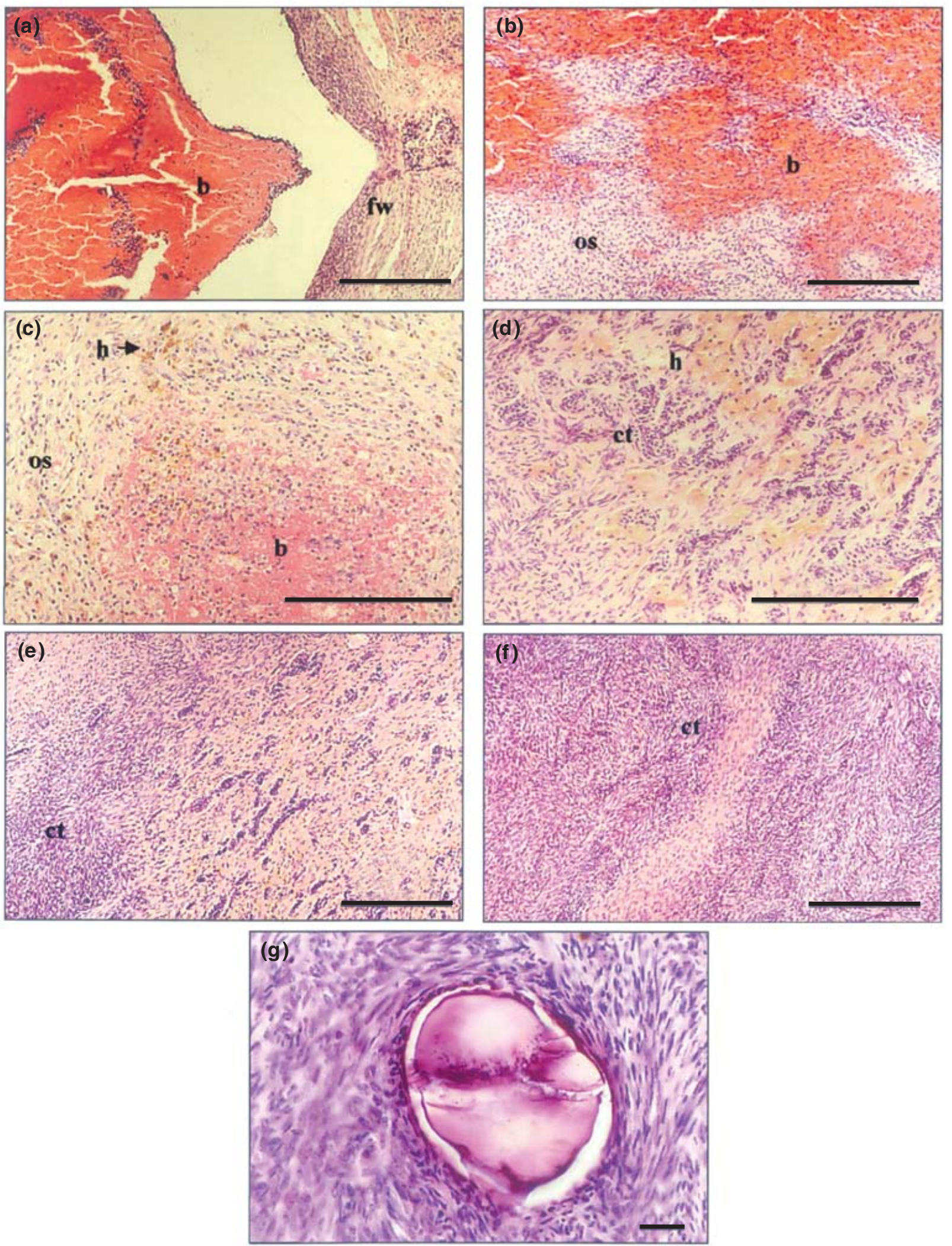

Fig. 7. For legend see facing page. 
stimulation was not higher for cows subjected to vaginal puncture.

Acute stress can affect production performances (Paape et al., 1973; Berning et al., 1987). In the present study, milk production after manipulation was significantly lower than the mean evening yield, with no difference between the two groups. This decrease may be due to a lower ingestion time in the morning of the experiment or to the stress of manipulation; nevertheless, the lack of difference between the two groups indicates that vaginal punctures are not responsible for milk production decreases. These two results indicate that transvaginal puncture is not responsible per se for acute stress.

As OPU sessions are typically performed twice per week over several weeks, this manipulation may also induce repeated acute stress responsible for adrenal desensitization (Gwazdauskas et al., 1980 and references therein; Ladewig, 1987). ACTH challenges demonstrated that repeated transvaginal punctures did not modify adrenal sensitivity. Moreover, the cortisol responses in the punctured group after each manipulation session remained identical during the 8 weeks of the experiment, confirming the absence of stress associated with repetition.

Repeated increases of blood cortisol concentrations have been shown to affect the immune system (Paape et al., 1981; Roth, 1985). Multiple ACTH injections are responsible for leucocytosis, mainly due to an increase in the number of circulating neutrophils, without significant changes in circulating lymphocytes or eosinophils (Wegner et al., 1976; Gwazdauskas et al., 1980; Paape et al., 1981; Berning et al., 1987). Lymphopenia is sometimes observed (Gwazdauskas et al., 1980). Moreover, within the specific confines of the test, repeated peritoneal penetrations associated with transvaginal follicular punctures may have produced some chronic infection. As both groups exhibited an equivalent leucocytosis after the experimental period, this increase was not a result of transvaginal puncture. The observed leucocytosis may have been caused by a transitory infection of the herd; however, there were no clinical signs, milk production decrease, or occurrence of mortality during or even after the experimental period.

Confirmation that the immune system remained unaffected by repeated punctures relied on milk somatic cell counts. No economically significant variation in milk cell counts were revealed by the present study. Various forms of stress have been demonstrated to induce abnormally high somatic cell counts (Wegner et al.,
1976), although some authors have not observed any correlation (Paape et al., 1973,1981; Berning et al., 1987). In the present study, no clinical infection was observed in punctured cows; in particular, there was no mastitis or vaginitis. These observations are important in terms of animal welfare, as well as for dairy economy, as OPU is practised in the field on high-producing dairy cows 1-2 months post partum, at the peak of lactation.

Overall, the results of the present study conclude that transvaginal punctures induce neither short-term nor long-term stress.

However, punctures may have other potential detrimental effects on the ovaries, as a result of multiple repeated penetrations by the collecting needle. Although several studies have macro- and microscopically examined ovaries after OPU sessions (for example Gibbons et al., 1994; Kruip et al., 1994; Petyim et al., 2001), to the authors' knowledge, the present study is the only study that has used a chronological approach (from 0 to 30 days after the last puncture). The objective of this work was to observe the ovarian healing process. Pieterse et al. (1988), Van der Schans et al. (1991), Bergfelt et al. (1994) and Gibbons et al. (1994) observed the presence of haemorrhagic follicles and blood collections in the cortex immediately after puncture and after 4 days. However, haemorrhagic foci organized very rapidly and no permanent lesions persisted in the ovaries. No adhesions were observed in the present study, confirming the results of Pieterse et al. $(1991 \mathrm{a}, \mathrm{b})$ and McEvoy et al. (2001). Some authors have described the appearance of a fibrous net around the ovaries (Gibbons et al., 1994), or a slight, local hardening of the ovarian tunica albugina or cortex (Pieterse et al., 1991a,b; Van der Schans et al., 1991; Boni et al., 1997; Petyim et al., 2000; McEvoy et al., 2001); these findings were not observed in the present study, even in cows submitted to $27 \mathrm{OPU}$ sessions. Healing was nearly complete after 10 days, without the development of an ovarian fibrosis despite multiple repeated needle punctures. In accordance with Van der Schans et al. (1991), Gibbons et al. (1994) and Petyim et al. (2001), some short-term limited trauma associated with follicular puncture followed by a rapid and complete healing of ovaries was observed. This observation is compatible with that of normal fertility after repeated OPU reported by several authors (for example, Gibbons et al., 1994; Kruip et al., 1994).

Furthermore, multiple intraovarian punctures do not seem to affect the intraovarian corpus luteum. During

Fig. 7. Histological examination of cow ovaries at different times after transvaginal puncture. (a,b) Immediately at the end of one puncture session. (a) Intrafollicular and (b) cortical haemorrhage. (c,d) Day 4 after the last of five puncture sessions. Regressing haemorrhagic focus with (c) haemosiderosis and (d) connective organization. (e) Connective organization at day 11. (f,g) Day 30: cortical fibrous tissue of (f) a haemorrhagic focus and (g) cortical calcification. b: blood; ct: connective tissue; fw: follicular wall; h: haemosiderosis; os: ovarian stroma. Scale bars represent (a-f) $100 \mu \mathrm{m}$ and (g) $10 \mu \mathrm{m}$. 
the puncture period, repeated transovarian needle penetrations interfere neither with normal secretion nor with regression of the corpus luteum (Kruip et al., 1994; Meintjes et al., 1995; present study). After regression of the initial corpus luteum, successive OPU performed every 3-4 days does not allow one follicle to dominate and ovulate (Bergfelt et al., 1994; Boni et al., 1997; Garcia and Salaheddine, 1998), so that the oestrous cycle is abolished (Gibbons et al., 1994; Stubbings and Walton, 1995; Boni et al., 1997; present study). No new corpus luteum formed until aspiration ended and progesterone concentrations remained low during the whole puncture period, as shown by Gibbons et al. (1994) and Kruip et al. (1994). In some cases, cows form luteal structures from follicular remnants, but with incomplete or abnormal luteinization (Stubbings and Walton, 1995; Petyim et al., 2001; Viana et al., 2001).

The present study validates repeated transvaginal ovarian punctures with regard to animal well-being, providing various objective arguments. As other manipulations (genital palpation, restraint, vaginal device set-up, and to some extent epidural anaesthesia) fall within wellaccepted and routinely performed procedures in cattle, these results may contribute towards a validation of the entire OPU procedure. These data may serve towards establishing a scientific basis for instituting regulations in the area of reproductive biotechnologies.

This work has been conducted with the financial support of the Scientific Council of the Ecole Nationale Vétérinaire d'Alfort. The authors are grateful to F. Pommier, C. Prevert, P. Laigre and F. Deniau for OPU and animal care at UCEA Bressonvilliers, and to J. P. Pichard at Ecole Nationale Vétérinaire d'Alfort. The authors also thank $M$. Gillespie for careful reading of the manuscript.

\section{References}

Alam MGS and Dobson H (1986) Effect of various veterinary procedures on plasma concentrations of cortisol, luteinising hormone and prostaglandin $F_{2}$ alpha metabolite in the cow Veterinary Record $\mathbf{1 1 8}$ $7-10$

Bergfelt DR, Lightfoot KC and Adams GP (1994) Ovarian synchronization following ultrasound-guided transvaginal follicle ablation in heifers Theriogenology 42 895-907

Berning LM, Paape MJ, Miller RH and LeDane RA (1987) N-Acetyl$\beta$-D-glucosaminidase activities, milk somatic cell counts, and blood leukocyte and erythrocyte counts in cows after heat-induced stress or after intravenous administration of adrenocorticotropic hormone American Journal of Veterinary Research 48 1157-1161

Boni R, Roelofsen MWM, Pieterse MC, Kogut J and Kruip TH (1997) Follicular dynamics, repeatability and predictability of follicular recruitment in cows undergoing repeated follicular puncture Theriogenology $\mathbf{4 8}$ 277-289

Broom DM and Johnson KG (1993) Assessing welfare: short-term responses. In Stress and Animal Welfare pp 87-110. Chapman and Hall, London

Callesen H (1998) European farm animal embryo technology-ethics and legislation AETE Newsletter 9 4-5

Chase CC, Larsen RE, Randel RD, Hammond AC and Adams EL (1995) Plasma cortisol and white blood cell responses in different breeds of bulls: a comparison of two methods of castration Journal of Animal Science 73 975-980
Dantzer R (1994) Animal welfare methodology and criteria Revue Scientifique et Technique de l'Office International des Epizooties $\mathbf{1 3}$ 291-302

Den Daas N and Callesen H (2000) Minutes of the Workshop on Animal Health and Welfare AETE Newsletter 11 14-17

Dobson H and Smith RF (2000) What is stress, and how does it affect reproduction? Animal Reproduction Science 60-61 743-752

Fell LR, Wells R and Shutt DA (1986) Stress in calves castrated surgically or by the application of rubber rings Australian Veterinary Journal $\mathbf{6 3}$ $16-18$

Fisher AD, Crowe MA, Alonso de la Varga ME and Enright WJ (1996) Effect of castration method and the provision of local anesthesia on plasma corticol, scrotal circumference, growth, and feed intake of bull calves Journal of Animal Science 74 2336-2343

Garcia A and Salaheddine M (1998) Effects of repeated ultrasoundguided transvaginal follicular aspiration on bovine oocyte recovery and subsequent follicular development Theriogenology $\mathbf{5 0}$ 575-585

Gibbons JR, Beal WE, Krisher RL, Faber EG, Pearson RE and Gwazdauskas FC (1994) Effects of once- versus twice weekly transvaginal follicular aspiration on bovine oocyte recovery and embryo development Theriogenology 42 405-419

Goodhand KL, Watt RG, Staines ME, Hutchinson JSM and Broadbent PJ (1999) In vivo oocyte recovery and in vitro embryo production from bovine donors aspirated at different frequencies or following FSH treatment Theriogenology 51 951-961

Gwazdauskas FC, Paape MJ, Perry DA and McGillard ML (1980) Plasma glucocorticoid and circulating blood leukocyte responses in cattle after sequential intramuscular injections of ACTH American Journal of Veterinary Research 41 1052-1056

Kruip TA, Boni R, Wurth YA, Roelofsen MWM and Pieterse MC (1994) Potential use of ovum pick-up for embryo production and breeding in cattle Theriogenology 42 675-684

Ladewig J (1987) Endocrine aspects of stress: evaluation of stress reactions in farm animals. In Biology of Stress in Farm Animals: an integrative approach pp 13-25 Eds PR Wiepkema and PWM Van Adrichem. Martinus Nijhoff, Dordrecht

Lauffenburger J, Quinton H, Marchal J, Richard C, Mormede P, Renard JP and Chastant-Maillard S (1999) Evaluation of stress associated to ovum pick-up in cow. 15th AETE congress, Lyon, 10-11 September (1999), p 178

Lefcourt AM, Bitman J, Kahl S and Wood DL (1993) Circadian and ultradian rhythms of peripheral cortisol concentrations in lactating dairy cows Journal of Dairy Science 76 2607-2612

McEvoy TG, Thompson H, Dolman DF, Watt RG, Reis A and Staines ME (2001) Consequences of epidural injection and transvaginal ovarian puncture in heifers used repeatedly for ultrasound-guided ovum pick-up Theriogenology 55530

Meintjes M, Bellow MS, Broussard JR, Paul JB and Godke RA (1995) Transvaginal aspiration of oocytes from hormone-treated pregnant beef cattle for in vitro fertilization Journal of Animal Science 73 967-974

Morisse JP, Cotte JP and Huonnic D (1995) Effect of dehorning on behaviour and plasma cortisol responses in young calves Applied Animal Behaviour Science 43 239-247

Paape MJ, Schultze WD and Miller RH (1973) Leukocytic response to adrenocorticotrophic hormone as influenced by the infectious history of the mammary gland Journal of Dairy Science 56 733-737

Paape MJ, Gwazdauskas FC, Guidry AJ and Weinland BT (1981) Concentrations of corticosteroids, leukocytes, and immunoglobulins in blood and milk after administration of ACTH to lactating dairy cattle: effects on phagocytosis of Staphylococcus aureus by polymorphonuclear leukocytes American Journal of Veterinary Research 422081 2087

Petyim S, Bage R, Forsberg M, Rodriguez-Martinez H and Larsson B (2000) The effect of repeated follicular puncture on ovarian function in dairy heifers Journal of Veterinary Medicine A 47 627-640

Petyim S, Bage R, Forsberg M, Rodriguez-Martinez H and Larsson B (2001) Effects of repeated follicular punctures on ovarian morphology and 
endocrine parameters in dairy heifers Journal of Veterinary Medicine A 48 449-463

Pieterse MC, Kappen KA, Kruip TA and Taverne MAM (1988) Aspiration of bovine oocytes during transvaginal ultrasound scanning of the ovaries Theriogenology 30 751-762

Pieterse MC, Vos PL, Kruip TA, Willemse AH and Taverne MAM (1991a) Characteristics of bovine estrous cycles during repeated transvaginal, ultrasound-guided puncturing of follicles for ovum pick-up Theriogenology 35 401-413

Pieterse MC, Vos PL, Kruip TA, Wurth YA, Van Beneden TH, Willemse AH and Taverne MAM (1991b) Transvaginal ultrasound guided follicular aspiration of bovine oocytes Theriogenology 35 19-24

Roth JA (1985) Cortisol as mediator of stress-associated immunosuppression in cattle. In Animal Stresss pp 225-243 Ed. GP Moberg. American Physiological Society, Bethesda

Schernthaner W, Wenigerkind H, Stojkovic M, Palma GA, MödI J and Wolf $\mathbf{E}$ (1999) Pregnancy rate after ultrasound-guided follicle aspiration in non-lactating cows from different breeds Journal of Veterinary Medicine 46 33-37

Stubbings RB and Walton JS (1995) Effect of ultrasonically-guided follicle aspiration on estrous cycle and follicular dynamics in Holstein cows Theriogenology 43 705-712
Tilbrook AJ, Turner AI and Clarke IJ (2000) Effects of stress on reproduction in non-rodent mammals: the role of glucocorticoids and sex differences Reviews in Reproduction 5 105-113

Van der Schans A, Van der Westerlaken LAJ, De Wit AAC, Eyestone WH and De Boer HA (1991) Ultrasound-guided transvaginal collection of oocytes in the cow Theriogenology 35288

Van Genderen A and De Vriend H (2000) La sélection en élevage et le consommateur Elevage et Insémination 295 13-31

Viana JHM, Ferreira AM, Camargo LSA, Sá WF, Arajo MCC, Fernandes CAC and Marques AP, Jr (2001) Effect of the presence of non-regressed follicles after oocyte pick-up on follicular dynamics of Bos indicus cattle Theriogenology 55534

Wegner TN, Schuh JD, Nelson FE and Stott GH (1976) Effect of stress on blood leucocyte and milk somatic cell counts in dairy cows Journal of Dairy Science 59 949-956

Received 12 August 2002.

First decision 11 October 2002.

Revised manuscript received 4 December 2002.

Accepted 12 December 2002. 